\title{
PERAN ZAKAT DALAM MENGENTASKAN KEMISKINAN
}

(Diajukan untuk memenuhi tugas mata kuliah zakat dan wakaf)

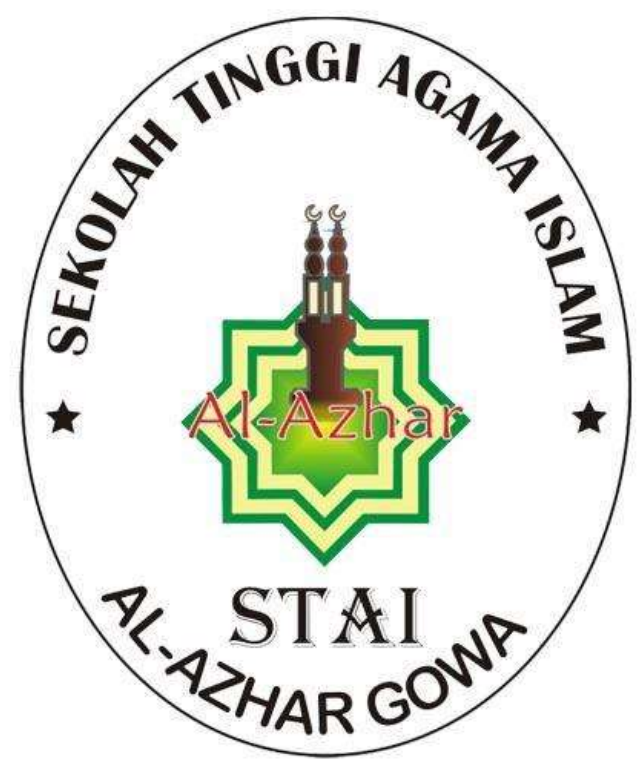

Oleh :

Nama : Nurul Fani

NIM : 1122020006

Prodi : Ekonomi Syariah

Dosen Pengampu : Samsul Arifai S.A.B.,M.A

\author{
STAI AL-AZHAR GOWA
}

TAHUN AJARAN 2020-2021 


\section{KATA PENGANTAR}

Puji syukur atas kehadirat Allah SWT. karena atas segala rahmat dan hidayah-Nya lah sehingga makalah ini dapat tersusun sampai dengan selesai. Tidak lupa juga kita panjatkan shalawat serta salam kapada junjungan kita nabi Muhammad SAW. karena sudah membawa kita dari zaman yang gelap gulita ke zaman yang terang benderang seperti sekarang ini.

Penulis berharap semoga makalah ini dapat menambah pengetahuan dan pengalaman bagi pembaca. Bahkan saya berharap lebih jauh lagi agar makalah ini bisa pembaca sekalian praktekkan dalam kehidupan sehari-hari.

Bagi saya sebagai penyusun merasa bahwa masih banyak kekurangan dalam penyusunan makalah ini karena keterbatasan pengetahuan dan pengalaman saya. Untuk itu saya sangat mengharapkan kritik dan saran yang membangun dari pembaca demi kesempurnaan makalah ini.

Makassar, 14 November 2021 


\section{DAFTAR ISI}

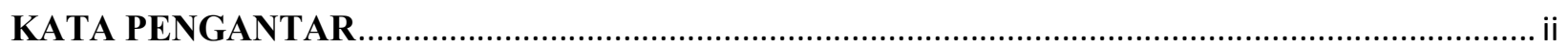

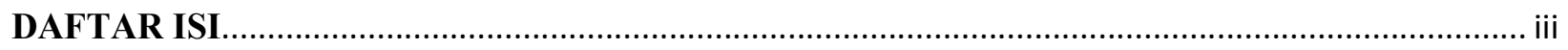

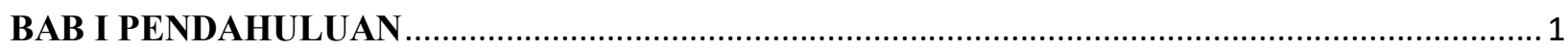

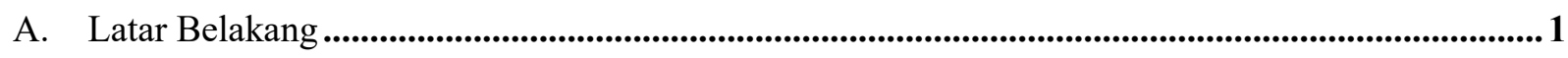

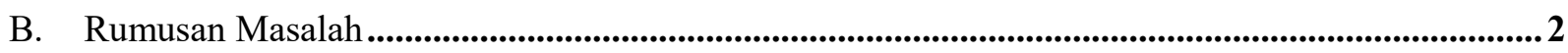

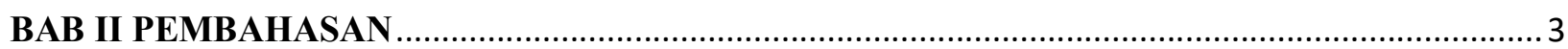

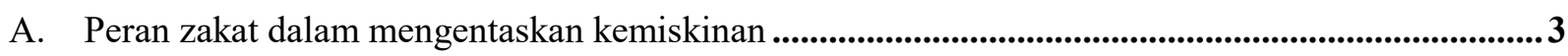

B. Dilihat dari segi pemanfaatannya zakat terbagi menjadi dua......................................................4

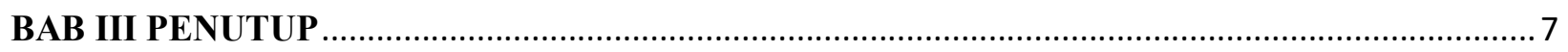

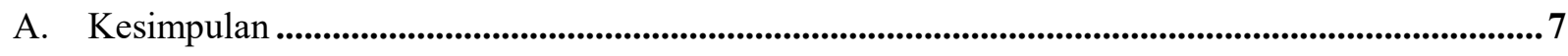

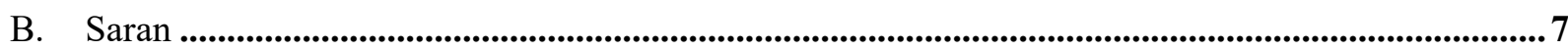

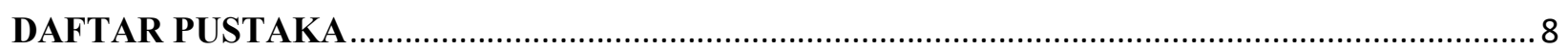




\section{BAB I \\ PENDAHULUAN}

\section{A. LATAR BELAKANG}

Menurut Hafidhuddin (2002) Zakat adalah salah satu pilar penting dalam ajaran Islam. Secara etimologis, zakat memiliki arti kata berkembang (an-namaa), mensucikan (at-thaharatu) dan berkah (al-barakatu). Sedangkan secara terminologis, zakat mempunyai arti mengeluarkan sebagian harta dengan persyaratan tertentu untuk diberikan kepada kelompok tertentu (Mustahik) dengan persyaratan tertentu pula. ${ }^{1}$

Sementara itu, al-Qardhawi (2002) mengatakan bahwa tujuan mendasar ibadah zakat itu adalah untuk menyelesaikan berbagai macam persoalan sosial seperti pengangguran, kemiskinan, dan lain-lain. ${ }^{2}$

Sedangkan kemiskinan merupakan masalah besar dan sejak lama telah ada, dan hal ini menjadi kenyataan di dalam kehidupan. Islam memandang bahwa masalah kemiskinan adalah masalah tidak terpenuhinya kebutuhan-kebutuhan primer secara menyeluruh. ${ }^{3}$ yang menyebabkan masyarakat kesulitan untuk membayar zakatnya.

Dengan itu Islam mempunyai perhatian khusus terhadap zakat untuk mengeluarkan masyarakat yang tidak mampu dari belenggu kemiskinannya dan beberapa penerima wajib zakat, dengan menggunakan zakat, infaq, dan sadaqoh.

Secara umum Al-Qur'an mengatakan bahwa zakat itu diambil dari setiap yang dimiliki, seperti dikemukakan dalam surat at-Taubah:103, yaitu:

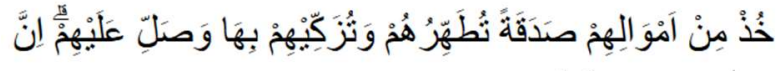

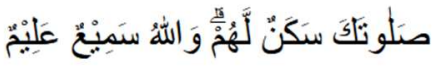

Artinya: Ambillah zakat dari harta mereka, guna membersihkan dan menyucikan mereka, dan berdoalah untuk mereka. Sesungguhnya doamu itu (menumbuhkan) ketenteraman jiwa bagi mereka. Allah Maha Mendengar, Maha Mengetahui.

\footnotetext{
${ }^{1}$ Irfan Syauqi Beik, "Irfan Syauqi Beik Analisis Peran Zakat Dalam Mengurangi Kemiskinan: Studi Kasus Dompet Dhuafa Republika," Pemikiran dan Gagasan 2, no. January 2009 (2009): 45-53.

2 Irfan Syauqi Beik.

${ }^{3} \mathrm{~N}$ Amrullah, Pengaruh Zakat Produktif dalam Bidang Usaha Mikro Terhadap Upaya Pengentasan Kemiskinan (study BAZNAS Kota Makassar), 2018, http://repositori.uin-alauddin.ac.id/id/eprint/14366.
} 
Dan juga diambil dari setiap usaha yang baik dan halal, seperti yang digambarkan dalam surat alBaqarah:267, yaitu:

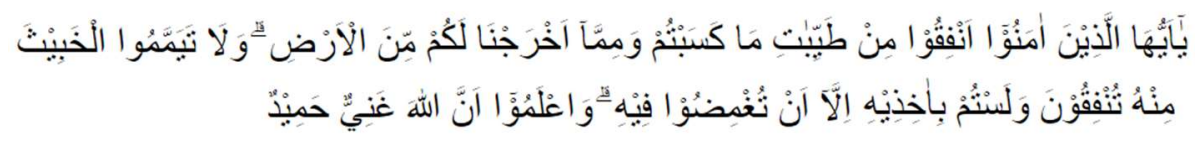

Artinya: Wahai orang-orang yang beriman! Infakkanlah sebagian dari hasil usahamu yang baik-baik dan sebagian dari apa yang Kami keluarkan dari bumi untukmu. Janganlah kamu memilih yang buruk untuk kamu keluarkan, padahal kamu sendiri tidak mau mengambilnya melainkan dengan memicingkan mata (enggan) terhadapnya. Dan ketahuilah bahwa Allah Mahakaya, Maha Terpuji.

\section{B. Rumusan Masalah}

1) Apa itu zakat?

2) Apa peran zakat terhadap masyarakat?

3) Bagaimana zakat mengatasi kemiskinan? 


\section{BAB II}

\section{PEMBAHASAN}

\section{A. Peran zakat dalam mengentaskan kemiskinan}

Badan Pusat Statistik (BPS) mencatat jumlah penduduk miskin Indonesia turun tipis sebanyak 0,04\% dari 27,55 juta pada September 2020 menjadi 27,54 juta. Angka tersebut naik jika dibandingkan dengan Maret 2020 sebesar 4,2\%. Masih tingginya angka kemiskinan Indonesia disebabkan pandemi Covid-19 yang masih melanda Indonesia. Berdasarkan persentase, penduduk miskin Indonesia sebesar 10,14\% pada Maret 2021. Angka ini hanya turun 0,05\% dibandingkan dengan September 2020 yang sebesar 10, 19\%. Sementara jika dibandingkan dengan tahun sebelumnya meningkat 0,36\% dari 9,78\%. Kemiskinan tertinggi di Pulau Maluku dan Papua sebesar 20,66\%. Kemiskinan tertinggi selanjutnya berasal dari Bali dan Nusa Tenggara 13,84\%, Sulawesi 10,29\%, dan Sumatera 10,15\%. Sementara persentase paling rendah terdapat di Pulau Jawa dan Kalimantan dengan persentase kemiskinan masingmasing 9,67\% dan 6,09\%. Berdasarkan wilayah, kemiskinan di perdesaan lebih tinggi dari perkotaan. Angka kemiskinan di perdesaan mencapai dua digit, yaitu 13,1\%. Sementara di perkotaan sebesar $7,89 \%{ }^{4}$

Meski pun dari data Badan Pusat Statistic (BPS) tersebut, angka kemiskinan di Indonesia menurun, namun masalah kemiskinan bagi bangsa Indonesia hingga saat ini masih menjadi dilema karena Indonesia jika dilihat dari sumber daya alamnya adalah sebuah negara yang dikaruniai kekayaan alam yang terhampar di daratan dan lautnya yang sangat luar biasa.

Penggiat zakat Indonesia Didin Hafidzuddin berpendapat bahwa masalah kemiskinan jika tidak ditangani secara integrative bisa menyebabkan terjadinya proses perubahan budaya bangsa yang sangat signifikan dari bangsa yang berbudaya ramah, suka bergotong royong, dan saling toleransi menjadi bangsa yang suka berfoya-foya, kasar, pemarah, dan kehilangan moralitas dan nilai-nilai kemanusiaannya.

Salah satu cara untuk memerangi kemiskinan umat Islam di Indonesia adalah dengan memberdayakan zakat. Pemberdayaan zakat ini hanya dapat dilakukan apabila kesadaran untuk membayar zakat sudah tinggi di kalangan umat. Dalam sejarah perjalanan masyarakat Islam, ajaran zakat sudah mulai dilupakan dan disempitkan artinya. Zakat seolah-olah hanya merupakan kewajiban individu dan dilaksanakan dalam rangka menggugurkan kewajiban individu terhadap perintah Allah ini. Zakat menjadi apa yang sering disebut sebagai ibadah mahzhah individu kaum muslimin. Dari suatu ajaran yang luas dan mendalam yang dikembangkan oleh Rasul dan Sahabat di Madinah, zakat menjadi sebuah ajaran yang sempit

\footnotetext{
4 BPSa, "Penduduk miskin Indonesia capai 27,54 orang per Maret 2021," no. September 2020 (2021): 2021, https://databoks.katadata.co.id/datapublish/2021/07/15/jumlah-penduduk-miskin-indonesia-capai-2754-permaret-2021.
} 
bersama mundurnya peranan Islam di panggung politik, ekonomi, ilmu, dan peradaban manusia. $^{5}$

Beberapa lembaga amil zakat di Indonesia, seperti badan amil zakat nasional (Baznas), Indonesia Magnificence of Zakat (IMZ), Dompet Dhuafa (DD) Republika, Rumah Zakat Indonesia (RZI), Forum Zakat (FOZ), dan lainnya, mencatat bahwa di Indonesia potensi zakat yang ada, baik perorangan maupun perusahaan, diperkirakan mencapai Rp 20-30 triliun per tahun. Jumlah ini, bila benar-benar bisa direalisasikan, niscaya akan membuat angka kemiskinan di Indonesia yang mencapai 35 juta jiwa akan segera teratasi. ${ }^{6}$

Untuk menguatkan keyakinan akan adanya perhatian ajaran Islam atas kesulitan hidup setiap muslim yang mengalami himpitan hidup dan kelemahan secara ekonomi, maka implementasi pengamalan ajaran zakat seharusnya menjadi semacam tawaran solutif bagi penanganan dan penanggulangan masalah kemiskinan bagi pemerintah Indonesia yang mayoritas penduduknya adalah muslim. Selain itu, ajaran Islam juga memang merupakan ajaran yang sangat menekankan setiap pemeluknya untuk giat berusaha dan bekerja keras agar dapat memperoleh rezki yang halal untuk diri dan keluarganya sebagai upaya memenuhi kebutuhan hidupnya tanpa harus menengadahkan tangan meminta kepada orang lain. Dan apabila di suatu situasi masyarakat muslim masih membutuhkan bantuan materil dan keuangan untuk mencukupi kebutuhan pokok mereka, maka ajaran zakat harus diupayakan maksimalisasi pengelolaannya agar dapat menjadi solusi atas usaha penanggulangan kemiskinan. ${ }^{7}$ Dengan demikian peran zakat sangat dibutuhkan sebagai penyaluran bantuan pertama terhadap para mustahik.

\section{B. Dilihat dari segi pemanfaatannya zakat terbagi menjadi dua}

Zakat produktif dan zakat konsumtif:

1. Zakat produktif

Zakat produktif adalah pemberian zakat yang dapat membuat para penerimanya menghasilkan sesuatu secara terus-menerus, dengan harta zakat yang telah diterimanya. Dengan kata lain zakat dimana harta atau dana zakat yang diberikan kepada para mustahik tidak dihabiskan akan tetapi dikembangkan dan digunakan untuk membantu usaha mereka, sehingga dengan usaha tersebut mereka dapat memenuhi kebutuhan hidup secara terus menerus. ${ }^{8}$

\footnotetext{
${ }^{5}$ M. Nasrullah, "Peran Zakat Sebagai Pendorong Multiplier Ekonomi," Jurnal Hukum Islam IAIN Pekalongan 13, no. 1 (2010): 37028, https://doi.org/10.28918/jhi.

6 2004:4 Departemen Agama, “Bab I Pendahuluan” Journal information 10, no. 3 (2009): 1-16.

${ }^{7}$ Mujetaba Mustafa, Ammar Munir, dan Ismail Kappaja, "Zakat dan Penanganan Kemiskinan," Al-Azhar Journal of Islamic Economics 2, no. 2 (2020): 104-17, https://doi.org/10.37146/ajie.v2i2.46.

${ }^{8}$ A. Amalia dan K. Mahalli, "Potensi Dan Peranan Zakat Dalam Mengentaskan Kemiskinan Di Kota Medan," Jurnal Ekonomi dan Keuangan 1, no. 1 (2012): 14869.
} 
Zakat produktif pun sangat berperan penting dalam kelangsungan hidup induvidu maupun masyarakat mustahik. Karena dengan adanya zakat produktif, induvidu maupun masyarakat dapat meningkatkan berbagai macam produktivitas maupun keahlian yang selama ini belum sempat tersalurkan karena keterbatasan biaya atau modal untuk mengembangkan keahliannya serta memodali usaha yang ingin ia kelola.

Dengan itu, zakat mampu berperan dalam penanggulangan kemiskinan, karena dalam pembentukan modal, zakat tidak hanya mendapatkan legitimasi oleh pemerintah, namun juga legitimasi oleh agama. Pembentukan modal semata-mata tidak hanya berasal dari pengolahan dan pemanfaatan sumber daya alam saja, tetapi melalui upaya penyisihan sebagian harta bagi yang mampu, yang wajib dibayarkan kepada pengelola zakat. Zakat juga mampu memaksimalkan potensi SDM (Sumber Daya Manusia) melalui pengadaan sarana dan prasarana bagi masyarakat, meningkatkan produktifitas, serta meningkatkan pendapatan masyarakat secara umum. ${ }^{9}$

Potensi zakat sangat terbuka lebar untuk mengatasi persoalan kesenjangan kaya dan miskin dengan syarat kebijakan dan manajemen zakat secara konprehensif dibenahi dan diberdayakan oleh pemerintah (hasil penelitian Kholilah CIES UB Malang 2011). ${ }^{10}$ Dengan pengolalaan zakat yang baik dan sesuai dengan aturan yang ada, maka zakat akan tersalurkan dengan baik. Dengan kata lain zakat akan mengatasi kemiskinan dengan memberikan beberapa prosedur terhadap mustahik.

\section{Zakat konsumtif}

Zakat konsumtif adalah memberikan dana zakat kepada mustahik tanpa di ikuti pemberdayaan mustahik. Selain itu zakat konsumtif juga adalah zakat yang ditujukan kepada para mustahik yang sudah tidak produksi lagi, contohnya para lansia dan lain sebagainya.

Nicham (2012) meneliti mengenai zakat konsumtif dan produktif pada Bapelurzam Kabupaten Kendal dan menemukan bahwa kedua tipe zakat tersebut memiliki kekurangan masing-masing. Pada zakat konsumtif, Bapelurzam Kabupaten Kendal kurang memiliki kesesuaian dengan esensi dari zakat konsumtif itu sendiri. Hal ini terjadi karena Bapelurzam Kabupaten Kendal lebih menekankan pada aspek adanya jasa yang telah diberikan oleh orangorang yang dimasukan ke dalam mustahik zakat. Pada zakat produktif, prakteknya kurang maksimal karena pemberian modal dalam jumlah yang kecil sehingga dampaknya kurang terlihat nyata pada mustahik.

Siswi (2016) meneliti mengenai salah satu program dari dana zakat konsumtif dan produktif, yaitu ZUM (Zakat untuk Mustahik) dan KUM (Kelompok Usaha Mandiri). Berdasarkan hasil penelitian, dana zakat yang diberikan telah mampu untuk mengubah pendapatan mereka, namun zakat yang diberikan belum mampu untuk mengubah akses pendidikan anak dan jaminan kesehatan keluarga sehingga dana zakat yang diberikan belum berperan secara maksimal terhadap kehidupan mereka. Selain itu, dana zakat yang diberikan

\footnotetext{
${ }^{9}$ Ihwan Wahid Minu, "Peranan Zakat dalam Penanggulangan Kemiskinan di Kota Makassar (Studi Kasus BAZNAS Kota Makassar)," Thesis, 2017, 1-196, http://repositori.uin-alauddin.ac.id/6260/1/Ihwan Wahid Minu.pdf.

${ }^{10}$ Martavevi Azwar, "Zakat, Fungsi Zakat, Dompet Dhuafa, Kesejahteraan Sosial 1," 2016.
} 
juga belum mampu untuk merubah penerima zakat produktif melalui program KUM (Kelompok Usaha Mandiri) menjadi seorang muzaki.

Yusuf Qardawi menguraikan tujuan zakat secara umum mejadi dua, yakni dampaknya bagi si pemberi dan dampaknya bagi si penerima.

Adapun dampaknya bagi si pemberi adalah sebagai berikut:

1) Zakat mensucikan jiwa dari sifat kikir

2) Zakat mendidik berinfak dan memberi

3) Berakhlak dengan akhlak Allah

4) Zakat merupakan manifestasi syukur atas nikmat Allah

5) Zakat mengobagi hati dari cinta dunia

6) Zakat mengembangkan kekayaan batin

7) Zakat menarik rasa simpati/cinta

8) Zakat mensucikan harta kecuali harta yang haram, dan

9) Zakat mengembangkan harta ${ }^{11}$

Selanjutnya dampak zakat bagi si penerima ada dua yakni membebaskan sipenerima dari kebutuhan dan menghilangkan sifat dengki dan benci.

\footnotetext{
${ }^{11}$ Ruslang Ruslang, Samsul Samsul, dan Mujetaba Mustafa, “Komitmen Perusahaan Menjadi Muzakki," Al-Azhar Journal of Islamic Economics 2, no. 1 (2020): 25-35, https://doi.org/10.37146/ajie.v2i1.26.
} 


\section{BAB III}

\section{PENUTUP}

\section{A. KESIMPULAN}

1. Menurut Hafidhuddin (2002) Zakat adalah salah satu pilar penting dalam ajaran Islam. Secara etimologis, zakat memiliki arti kata berkembang (an-namaa), mensucikan (at-thaharatu) dan berkah (al-barakatu). Sedangkan secara terminologis, zakat mempunyai arti mengeluarkan sebagian harta dengan persyaratan tertentu untuk diberikan kepada kelompok tertentu (Mustahik) dengan persyaratan tertentu pula.

2. Sementara itu, al-Qardhawi (2002) mengatakan bahwa tujuan mendasar ibadah zakat itu adalah untuk menyelesaikan berbagai macam persoalan sosial seperti pengangguran, kemiskinan, dan lain-lain.

3. Salah satu cara untuk memerangi kemiskinan umat Islam di Indonesia adalah dengan memberdayakan zakat. Pemberdayaan zakat ini hanya dapat dilakukan apabila kesadaran untuk membayar zakat sudah tinggi di kalangan umat. Dalam sejarah perjalanan masyarakat Islam, ajaran zakat sudah mulai dilupakan dan disempitkan artinya. Zakat seolah-olah hanya merupakan kewajiban individu dan dilaksanakan dalam rangka menggugurkan kewajiban individu terhadap perintah Allah ini. Zakat menjadi apa yang sering disebut sebagai ibadah mahzhah individu kaum muslimin. Dari suatu ajaran yang luas dan mendalam yang dikembangkan oleh Rasul dan Sahabat di Madinah, zakat menjadi sebuah ajaran yang sempit bersama mundurnya peranan Islam di panggung politik, ekonomi, ilmu, dan peradaban manusia

\section{B. SARAN}

Berdasarkan makalah diatas, maka penulis berharap kita bisa memahami peran zakat dalam mengentaskan kemiskinan. Kita bisa mengurangi kemiskinan dengan menggalakkan zakat dan menyalurkannya kepada para mustahik dengan baik dan benar. 


\section{DAFTAR PUSTAKA}

Amalia, A., dan K. Mahalli. "Potensi Dan Peranan Zakat Dalam Mengentaskan Kemiskinan Di Kota Medan." Jurnal Ekonomi dan Keuangan 1, no. 1 (2012): 14869.

Amrullah, N. Pengaruh Zakat Produktif dalam Bidang Usaha Mikro Terhadap Upaya Pengentasan Kemiskinan (study BAZNAS Kota Makassar), 2018. http://repositori.uinalauddin.ac.id/id/eprint/14366.

Azwar, Martavevi. “Zakat, Fungsi Zakat, Dompet Dhuafa, Kesejahteraan Sosial 1,” 2016.

BPSa. "Penduduk miskin Indonesia capai 27,54 orang per Maret 2021," no. September 2020 (2021): 2021. https://databoks.katadata.co.id/datapublish/2021/07/15/jumlah-pendudukmiskin-indonesia-capai-2754-per-maret-2021.

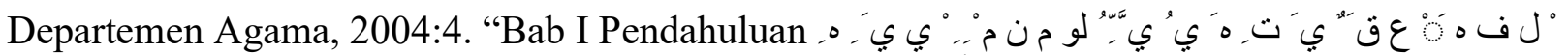

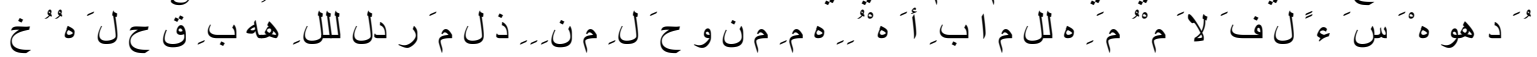

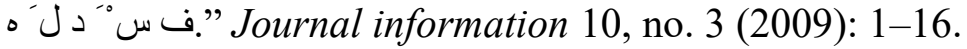

Irfan Syauqi Beik. "Irfan Syauqi Beik Analisis Peran Zakat Dalam Mengurangi Kemiskinan: Studi Kasus Dompet Dhuafa Republika.” Pemikiran dan Gagasan 2, no. January 2009 (2009): 45-53.

Minu, Ihwan Wahid. "Peranan Zakat dalam Penanggulangan Kemiskinan di Kota Makassar (Studi Kasus BAZNAS Kota Makassar).” Thesis, 2017, 1-196. http://repositori.uinalauddin.ac.id/6260/1/Ihwan Wahid Minu.pdf.

Mustafa, Mujetaba, Ammar Munir, dan Ismail Kappaja. "Zakat dan Penanganan Kemiskinan." Al-Azhar Journal of Islamic Economics 2, no. 2 (2020): 104-17. https://doi.org/10.37146/ajie.v2i2.46.

Nasrullah, M. "Peran Zakat Sebagai Pendorong Multiplier Ekonomi." Jurnal Hukum Islam IAIN Pekalongan 13, no. 1 (2010): 37028. https://doi.org/10.28918/jhi.

Ruslang, Ruslang, Samsul Samsul, dan Mujetaba Mustafa. "Komitmen Perusahaan Menjadi Muzakki." Al-Azhar Journal of Islamic Economics 2, no. 1 (2020): 25-35.

https://doi.org/10.37146/ajie.v2i1.26. 